\title{
THE CONSTRUCTION AND TESTING OF A GLUED LAMINATED WOODEN ARCH OF 47-FOOT SPAN
}

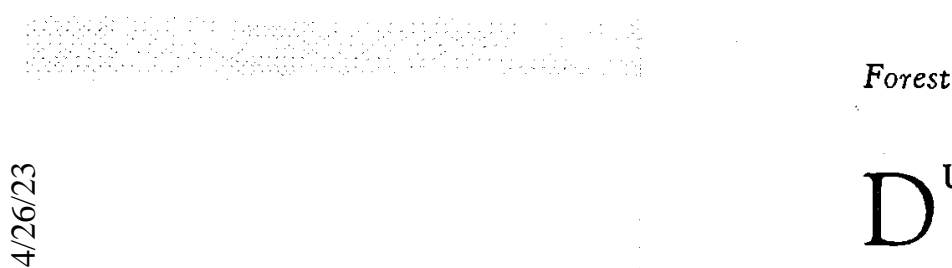

By D. E. KeNNEDY

Forest Products Laboratories, Dominion Forest Service, Ottawa, Ontario

\section{INTRODUCTION}

Anis has been due, in part, to the extensive use of this type of construction in Europe, where glued, laminated beams and arches have been employed for about 30 years. It was greatly accelerated during World War II, when the United States and Canada were short of steel for building construction and it was necessary to find new methods of utilizing timber in construction.

A considerable number of buildings erected during the war employed such types of construction as glued, laminated beams, arches and bow-string truss chords. Most of this work was done with a limited amount of information regarding the best methods of design, and with little or no experience on the part of the designing engineers. It was known that a properly made glue joint may be stronger than the wood itself, but most of the other factors involved were not familiar to the average structural designer, who suddenly found himself faced with the problem of designing a structure involving a novel use of wood and a novel method of fastening it together.

The practicability of this type of construction is clearly indicated by the success with which these many buildings performed the services for which they were intended. Although the stimulus of a steel shortage is no longer operative, laminated construction has won a place in the construction field on its own merits, particularly in those buildings or structures where special consideration such as size, span, or appearance are determining factors. It now remains to demonstrate to the architectural and engineering professions, and to the construction industry as a whole, what can be done in the way of glued, laminated, wooden construction and how it can best be ac. complished.

\section{Purpose of THE INVESTIGATION}

The Forest Products Laboratories of Canada have been actively interested in the technical aspects of glued, laminated, wooden construction for a number of years. A considerable amount of basic research has been carried on to determine the strength, durability, and moisture resistance of various types of glue when used with woods of various species. In addition, some work has been done which is aimed in particular toward the use of glue in laminated beams and arches.

This latter work has included an investigation into the strength properties of full-size laminated beams, glued together with two basic types of glue and pressed together with both nail pressure and clamping pressure. A long-term experiment has also been undertaken which will yield, over a period of ten years, valuable data concerning the durability of laminated 


\section{LAMINATED ARCH - KENNEDY}

beams when glued with three basic types of glue and then exposed to the weather continuously for varying periods of time. More experimental work of a similar nature is contemplated, and the Laboratory expects to give continuing attention to the problems of glued and laminated construction for some years to come.

The construction and testing of a large structural arch were considered to be important phases of the general investigation into the strength properties of glued, laminated construction. The arch selected for the test was designed by the author to suit the requirements of a particular type of building. The type of building referred to is one which would be suitable for auditoriums, drill halls, recreation rooms, testing and research laboratories, or any other use calling for large rooms with unobstructed floor space.

\section{Method OF DESIGN}

In designing the laminated ach, the requirements of the National Building Code were adhered to in assuming probable roof loads. The working stresses in shear and flexure were chosen on the strength of data, assembled by the Laboratory, pertaining to the strength properties of white spruce of the grade to be employed.

The arch was designed to fit inside a building with an inside width of 47 feet 6 inches, a height-to underside of roof at the peak-of 21 feet 6 inches, and a wall height--to underside of roof-of 14 feet 3 inches. The spacing of the arches along the length of the building was 11 feet on centres.

The dead load of the roof itself was about 14 pounds per square foot. The assumed weight of the snow was 40 pounds per square foot of the horizontally projected area. The arch was designed to support this total load with what was considered to be an ample margin of safety.

The width of the arch rib was constant throughout at 11 inches. The depth of the rib varied from $101 / 2$ inches at the footings and ridge to $25-3 / 8$ inches at the haunch or curved portion. The white spruce lumber was pur. chased in widths of 4,6 , and 8 inches and in random lengths of 12 to 18 feet. The nominal thickness of the boards before dressing was one inch and the boards were dressed before assembly to thicknesses of $11 / 16,3 / 4,13 / 16$, and $7 / 8$ inches, whichever could be obtained most economically. The 11 . inch width of the arch rib was obtained by using $31 / 2,53 / 8$, and $71 / 2$ inch boards, in an overlapping pattern in each succeeding layer in the arch.

\section{CONSTRUCTION}

The arch was constructed by the staff of the Laboratory. The lumber used was commercial white spruce of select merchantable and merchantable grades. The glue was a good commercial grade of casein. The means of applying gluing pressure consisted mainly of 2 -inch nails.

White spruce was chosen because it was believed to set a precedent in laminated construction of this type. Laminated arches of certain other species had been constructed and used in quite appreciable numbers. It was intended to show that, for laminated arches of moderate span, white spruce was a suitable structural material. 
Casein glue was selected because it was known to be effective in relatively thick glue lines, and also because of its known durability under dry conditions such as would obtain in a heated building. Casein glue is also easy to mix, can be used on wood with a fairly wide range of moisture content, is not seriously affected by small errors in proportioning, and will set firmly at room temperatures.

The gluing pressure was provided by nails in order to demonstrate the ultimate in simplicity of construction. Few woodworking shops would be without sufficient equipment to build a laminated arch by this method. Clamping pressure has always been considered better than nailing pressure because it provides greater unit gluing pressure, resulting in thinner glue lines. It was intended to demonstrate, however, that sufficient glue-line strength could be achieved by nailing; and that clamping pressure, though admittedly the optimum, was not necessary in this instance.

Before a lamination was installed in the arch, the lumber was end-glued to make up a length equal to the perimeter of one-half of the arch. These end joints were effected by the use of 1 in 12 plain tapered scarfs which were glued together, several laminations at a time, in a screw press.

It was necessary to subject each lamination to a steaming treatment before it was bent over the form. Several laminations were placed in a narrow box about eight feet long with slots in the ends and a closely fitting cover. Live steam was piped into this box for a period of one or two hours, after which the laminae were removed from the box and immediately bent over the form. Care was taken to insure that the casein-glued scarfed joints were outside and some distance from the box, where they would be unaffected by the steaming.

The form was constructed to the contours of the inside face of the halfarch. It was erected on the floor of a shed and was carefully aligned and rigidly braced. As the laminations were added to the arch, glue was spread on both gluing faces and on the abutting interior edges by means of brushes. The boards were then placed quickly on the form and nailed firmly to the preceding laminations.

Two rows of 2 -inch common bright steel wire nails were used in each board, or four rows in the width of the arch rib. The nails were spaced at intervals of about six inches along each row and the rows themselves were spaced about one inch from the edge of each board.

The first (inner) seven laminae were full-length, running from footing to crown hinge. Starting with the eighth lamina, however, each successive piece was made slightly shorter than the previous one, until twenty such pieces had been applied, the last being of such a length that it completely traversed the haunch of the arch, running out at the tangent points. This procedure was adopted because the design, for structural reasons, called for a considerably greater depth at the haunch than at the footing or the crown hinge. The stepped surface was then planed down to two straight surfaces tangent to the curve of the arch, and construction was completed by applying to the outer face eight full-length laminae from footing to crown hinge. 
When the glue had set, the arch was planed and sanded to a smooth finish, the ends were trimmed off to the proper angle, and the entire structure was given a coat of lead paint to protect it from rain during erection. The arch, when completed, had a depth at the haunch of $25.3 / 8$ inches, as against $101 / 2$ inches at footings and crown hinge.

\section{CROWN Hinge}

Although the arch was three-hinged in design, no provision was made to install frictionless pins at the three hinges. The arch was intended to be carried on flat footings and the lower end of each portion was therefore cut off square; the top ends were cut off at an angle such that the arch would abut at the crown along a vertical plane.

The halves of the arch were joined at the crown hinge by a simple sleeve welded from three-eighths-inch steel plate. This was made to fit tightly at the sides, but loosely at top and bottom, to allow for deflection under test loading.

\section{ERECTION}

The arch was erected outdoors, as there was insufficient head room in any of the buildings of the Laboratory. It was erected under four timber bents, each bent consisting of a pair of 6-inch square verticals capped with 6 by 10 -inch timbers. The bents were rigidly X-braced to prevent the arch from deviating from the vertical plane during testing.

The arch was supported on spread footings which rested on a foundation of clay covered by about five feet of fill. The footings consisted of four railway ties on the flat, each 8 feet long 9 inches wide and seven inches high, bridged by two 7 by 9 inch timbers on edge.

The horizontal thrust of the arch at the supports was taken by two $7 / 8$ inch round steel rods fastened by nuts and washers to a pair of 3 -inch steel channels at each end.

\section{TESTING}

The load was applied by the use of eight large wooden boxes, each capable of holding 64 cubic feet of sand. The boxes were supported from the top surface of the arch by means of half-inch steel rods uniformly spaced along the span of the arch. In order to prevent a serious accident to the workmen loading the arch, two rows of timbers were placed on the ground beneath the boxes, with a scant two-inch clearance between the boxes and the timbers. If a sudden failure had occurred during loading, the arch would have been completely relieved of load after a deflection of 2 inches. As normal deflection progressed during loading, the safety timbers were adjusted to maintain adequate clearance beneath the boxes.

At regular intervals during the loading operation, deflection readings were taken at three places on the arch-at the crown hinge and at points about 10 feet on either side of the crown hinge. Readings were also taken of the settlement of the footings in relation to an established datum.

The calculated dead load of the roof was slightly under 7,400 pounds. The loading apparatus itself weighed nearly 3,800 pounds. It was necessary, therefore, to add 450 pounds of sand to each box to obtain a condition equal 
to dead loading only. The sand was added to each box in increments of 100 pounds and deflection readings were taken after each increment had been added.

After the dead load had been applied, the "snow load" was applied to one-half of the arch only. The load was applied to the north half of the arch in increments of 200 pounds per box until the four boxes each contained 3,000 pounds of sand. As would be expected, the north quarter point deflected considerably more than the south quarter-point under this eccentric loading.

The full "snow load" was then applied to the south half-arch in increments of 200 pounds per box. Under conditions of full dead and full snow load over the whole arch, the following conditions were observed:

Vertical deflection of north quarter-point .. 0.90 inches

Vertical deflection of crown hinge ....... 1.51 inches

Vertical deflection of south quarter-point .. 0.80 inches

Total horizontal deflection

7 feet above footings .............. 1 inch

The total superimposed load under the above conditions was 27,800 pounds.

After the full live load had been applied to the whole arch, the overload was applied in increments of 100 pounds per box in each of the eight boxes. This loading procedure was continued until each box contained 5,600 pounds of sand, giving a total applied load of 48,600 pounds. This load is equivalent to the following:

Dead load of roof $\ldots \ldots \ldots \ldots, 14$ pounds per sq. ft.

Snow load on roof $\ldots \ldots \ldots \ldots, 40$ pounds per sq. ft.

Overload .............. 40 pounds per sq. ft.

Under conditions of overload, the following readings of deflection were obtained:

Vertical deflection of crown hinge ...... 2.59 inches

Vertical deflection of north quarter-point .. 1.49 inches

Vertical deflection of south quarter-point .. 1.40 inches

Total horizontal deflection

7 feet above footings ............. 15/8 inches

During the whole of the loading process, the arch behaved very well and showed no sign whatever of incipient failure. However, one of the inherent characteristics of wood is its ability to withstand very heavy loads of short duration. This is a desirable quality, since structures are sometimes called upon to withstand loads greatly in excess of those contemplated in the design. These loads include accidental overloads caused by human error, earthquake and hurricane loads, and freak snowfalls.

It was decided, therefore, to leave the arch under overload for a period of several months and to continue the observations of deflection in order to determine if the arch were capable of supporting the load on a long-term basis. Accordingly, the arch was left under overload for the remainder of the winter and readings of deflection were taken at intervals of about one week. 


\section{LAMINATED ARCH - KENNEDY}

The stiffness of wood, that is, its resistance to deformation under load, is expressed technically as the modulus of elasticity. Wood has both a shortterm and a long-term modulus of elasticity. In other words, a rapidly. applied load will deflect a beam or joist a certain amount. If the load is left on the beam for a long period of time, it will be found that additional deflection has taken place. If the load is left on for a still longer time, it will be found that the deflection has become, for all practical purposes, constant, if the load is not in excess of a safe limit.

The crown hinge of the arch deflected 2.59 inches as soon as the load of 48,600 pounds had been applied. During the following two weeks, the deflection increased by about 0.26 inch. It required five more weeks for the deflection to increase another 0.27 inch. After the overload had been on the arch for seven weeks, the additional deflection, if any occurred, could not be measured with the instrument employed, an engineer's level. It may be assumed, therefore, that no further deflection of practical significance is taking place.

At the time of writing, the arch has been carrying its overload for more than four-and-a-half months. Its performance has been quite satisfactory and it is believed that the experiment has demonstrated that further economy of material may be effected in this type of construction without reducing the strength of the structure below a safe limit. 